\title{
Effects of a Glutamine Enema on Anastomotic Healing in an Animal Colon Anastomosis Model
}

\author{
Mani Habibi, Osman Zekai Oner ${ }^{1}$, Mehmet Tahir Oruc ${ }^{1}$, Nurullah Bulbuller², Sebahat Ozdem², \\ Sukru Ozdemir ${ }^{4}$, Arsenal Sezgin Alikanooglu ${ }^{5}$, Rojbin Karakoyun ${ }^{1}$, Ugur Dogan ${ }^{1}$, Ayper Ongen ${ }^{1}$, Umit Koc ${ }^{1}$ \\ Department of General Surgery, Esenler Maternity and Child Health Hospital, Istanbul; ${ }^{1}$ Department of General Surgery, Antalya Training \\ and Research Hospital, Antalya; Departments of ${ }^{2}$ General Surgery and ${ }^{3}$ Biochemistry, Akdeniz University, School of Medicine, Antalya; \\ ${ }^{4}$ Department of General Surgery, Karapınar State Hospital, Konya; ${ }^{5}$ Department of Pathology, Antalya Training and Research Hospital, \\ Antalya, Turkey
}

Purpose: Anastomotic leakage in colorectal surgery is a very important issue. Although many studies have shown the positive effects of enteral glutamine (Gln) on anastomotic healing, none has assessed the effects of administering Gln via an enema for anastomotic healing. To fill this study gap, this study investigated the intraluminal effect of administration of Gln enema on the healing of colonic anastomosis in a rat model.

Methods: Thirty Wistar albino rats were divided into three groups containing 10 rats each and were subjected to distal left colon transection and anastomosis. Postoperatively, group I (the control group) was administered no treatment, group II was administered daily placebo enemas containing physiological saline, and group III was administered daily $2 \%$ L-Gln enemas. After sacrifice on postoperative day 5, anastomotic healing, burst pressure, tissue hydroxyproline levels, and histological parameters were measured, and group values were compared via statistical analysis.

Results: Group III was found to have the highest mean bursting pressure and tissue hydroxyproline levels and the lowest mean ischemia score. While the values of these parameters were not found to differ significantly among the groups, the lack of significance may have been due to the limited number of subjects examined.

Conclusion: Administration of a Gln enema may have a positive effect on anastomosis in terms of bursting pressure and histopathological parameters. Future research should examine administration of a preoperative Gln enema as a means of decreasing the traumatic effects of the enema and identifying its applicability in surgical practice.

Keywords: Surgical anastomosis; Anastomotic Leak; Enema; Glutamine; Hydroxyproline

\section{INTRODUCTION}

Every year, thousands of intestinal anastomosis surgeries are performed worldwide. The reported incidence of anastomotic leakage from these procedures has been reported to range from $2 \%$ to

Received: September 26, 2015 - Accepted: October 16, 2015

Correspondence to: Mani Habibi, M.D.

Department of General Surgery, Esenler Maternity and Child Health

Hospital, Havaalanı Mh., Taşocağı Cd. No: 19 Esenler, Istanbul, Turkey

Tel: +90-5556788927, Fax: +90-212-629-13-03

E-mail:manihabibi@gmail.com

(c) 2015 The Korean Society of Coloproctology

This is an open-access article distributed under the terms of the Creative Commons Attribution NonCommercial License (http://creativecommons.org/licenses/by-nc/3.0) which permits unrestricted non-

commercial use, distribution, and reproduction in any medium, provided the original work is properly cited.
5\% [1]. Despite developments over the last 50 years, anastomotic complications remain the major complications of gastrointestinal anastomosis, and the procedure continues to pose the risk of morbidity and mortality [2]. A particularly troubling outcome of colorectal anastomosis is leakage, which affects up to $11 \%$ of patients and can lead to even more serious outcomes due to heavy fecal content $[3,4]$. Surgeons are very concerned with this high leakage rate and the morbidity and mortality associated with it. As even the most experienced and technically proficient surgeons may confront leakage, development of specific technical applications and pharmacological agents for better anastomotic healing and reduction in leakage has been a major research topic in contemporary surgery.

Glutamine (Gln) is the most abundant amino acid in the plasma and the free amino acid pool of the body [5]. While considered a 
nonessential amino acid under normal circumstances, Gln is considered essential during periods of severe disease and malnutrition [6]. When the intracellular concentration of Gln is reduced during surgery, trauma, sepsis, and other severe conditions, body stores are rapidly depleted $[7,8]$. With its trophic effects on the intestinal mucosa and mitigation effect on permeability, Gln is indispensable for the maintenance of intestinal metabolism and function $[9,10]$.

Based on these findings, administration of oral Gln or glutamic acid has been recommended as a means of supporting the basal membrane after bowel surgery and reducing the side effects of bowel surgery [10]. Perioperative Gln support has been reported to increase anastomosis durability by improving epithelial integrity via increasing the amount of mature collagen and accelerating healing [5, 11-14]. In a colitis model, prophylactic use of topical Gln was shown to reduce colonic inflammation $[15,16]$. Supporting this finding, Wischmeyer et al. [17] found administration of topical Gln to be effective in $60 \%$ of cases of chronic pouchitis examined.

Administration of a Gln enema has been shown to have positive effects on mucosal healing in inflammatory bowel disease and chronic pouchitis. However, to our knowledge, no study has evaluated the effects of Gln enema on anastomotic healing. To fill this study gap, we investigated the effects of administration of a Gln enema on anastomotic healing in an animal model.

\section{METHODS}

This experimental study was performed at Akdeniz University Faculty of Medicine, Experimental Medicine and Animal Laboratory, Antalya, Turkey. Permission to conduct the study was obtained from the Akdeniz University Animal Research Ethics Committee, and all procedures were conducted in accordance with the Code of Ethics of the World Medical Association (Declaration of Helsinki) for experiments involving animals. Thirty male Wistar albino rats were divided into three groups containing 10 rats each and were subjected to distal left colon transection and anastomosis. Postoperatively, group I (the control group) was administered no treatment, group II was administered $2 \mathrm{~mL}$ of physiological saline via an enema (i.e., placebo enema) daily, and group III was administered $2 \%$ cc of L-Gln via an enema (Sigma Aldrich Co., St. Louis, MO, USA) daily. The subjects were maintained in a constant environment (temperature $23^{\circ} \mathrm{C}$ and humidity $55.5 \%$ ) and were fed standard laboratory chow and tap water both preoperatively and postoperatively.

\section{Surgery}

Surgery was performed under nonsterile, but clean, conditions between $9 \mathrm{AM}$ and $12 \mathrm{AM}$ to avoid the effects of diurnal changes. After a 12-hour fast, subjects were anesthetized by using an intraperitoneal injection of $10 \mathrm{mg} / \mathrm{kg}$ xylazine (Rompin, Bayer, Istanbul, Turkey) and $50 \mathrm{mg} / \mathrm{kg}$ of ketamine hydrochloride (Vial Keta- lar, Eczacibasi, Istanbul, Turkey). All surgeries were performed by a single surgeon blind to the subjects' grouping. After the lab assistants/nurses had cleansed the skin with $10 \%$ povidone iodine (Isosol, Central Lab, Instanbul, Turkey), the surgeons achieved abdominal access through a $3-\mathrm{cm}-$ long midline incision. A colonic segment $3 \mathrm{~cm}$ above the peritoneal reflection was transected before standardized end-to-end anastomosis was performed by using eight interrupted sutures with $6 / 0$ polypropylene $(6 / 0$, Atraumatic Suture Prolene, Ethicon, Johnson \& Johnson, Brussels, Belgium). Three $\mathrm{mL}$ of saline solution was injected to prevent dehydration, and the fascia and skin were closed with $3 / 0$ silk-interrupted sutures (Dogsan, Istanbul, Turkey). Oral intake was resumed 6 hours postsurgery.

\section{Treatment}

Every day from postoperative day 1, all subjects in groups II and III were administered an enema every 12 hours. Under ether anesthesia, an 8-French feeding tube lubricated with $12.5 \mathrm{~g}$ of lidocaine hydrochloride jelly (Cathejell, Taymed, Istanbul, Turkey) was inserted into the anus for infusion of the enema (Fig. 1). After

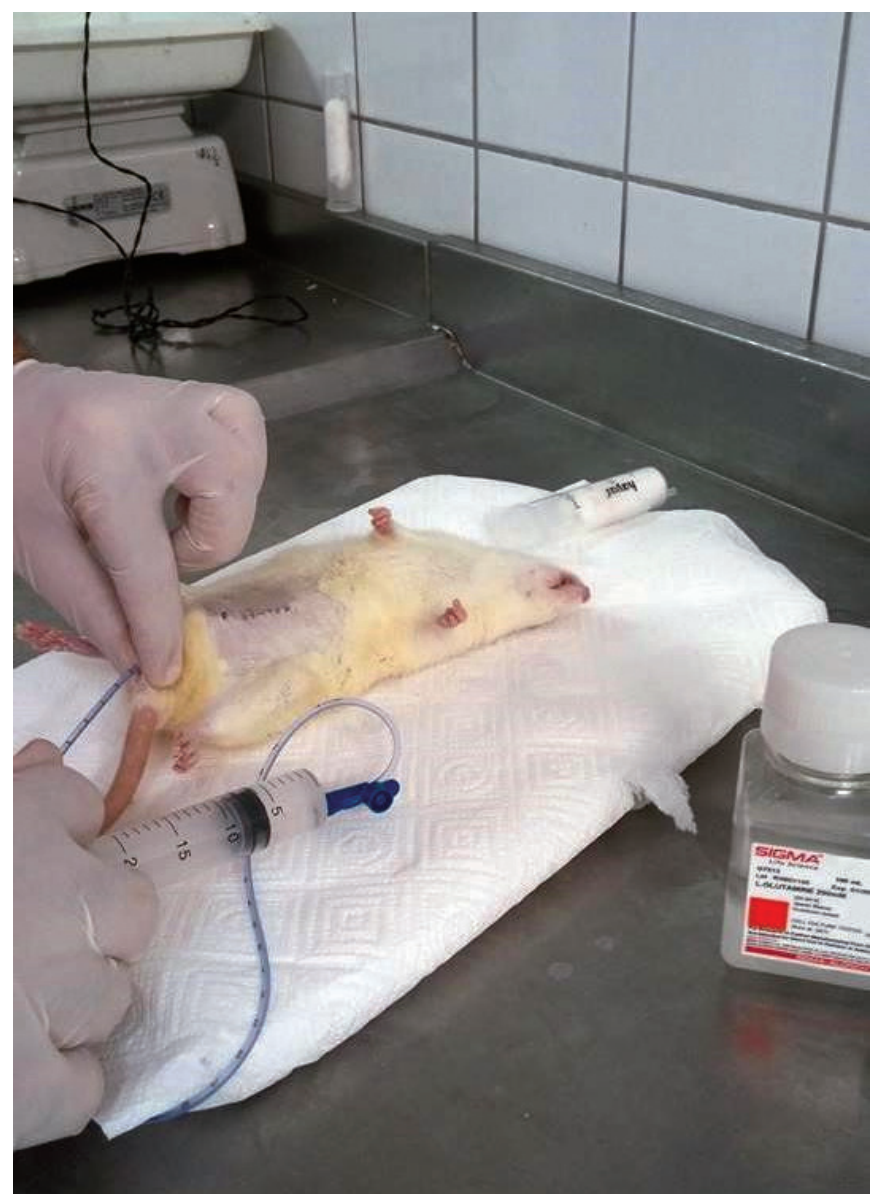

Fig. 1. Administration of glutamine enema. 
infusion the rats were maintained in an inverted position for 30 seconds to ensure uniform distribution of the liquid.

\section{Measurement of anastomotic bursting pressure}

After sacrifice on postoperative day 5, the abdomen was reopened, and the segment of anastomosis was located. While adhesions were protected to prevent damage to the anastomosis, abscesses, anastomotic separations, and leakages were carefully identified and examined. After fecal content had been removed to the proximal side, the proximal side of the anastomosis was clamped, and an 8-French catheter connected to a monitor (Nihon Kohden BSM-411, Tokyo, Japan) by a pressure transducer (Transpac IV, Abbott, Morgan Hill, CA, USA) was introduced from the anus. After the anus had been closed with a 1-0 silk Ushaped suture, $6 \mathrm{~mL} / \mathrm{min}$ of liquid was infused into the colon through a catheter inserted into the distal side by using a perfusion pump (Sapphire Infusion Pump, Q-Core, Tel Aviv, Israel) and was monitored (Fig. 2). The pressure level at the time of fluid leakage or the pressure level at which a sudden pressure drop occurred, as measured on the monitor, was recorded as the anasto-

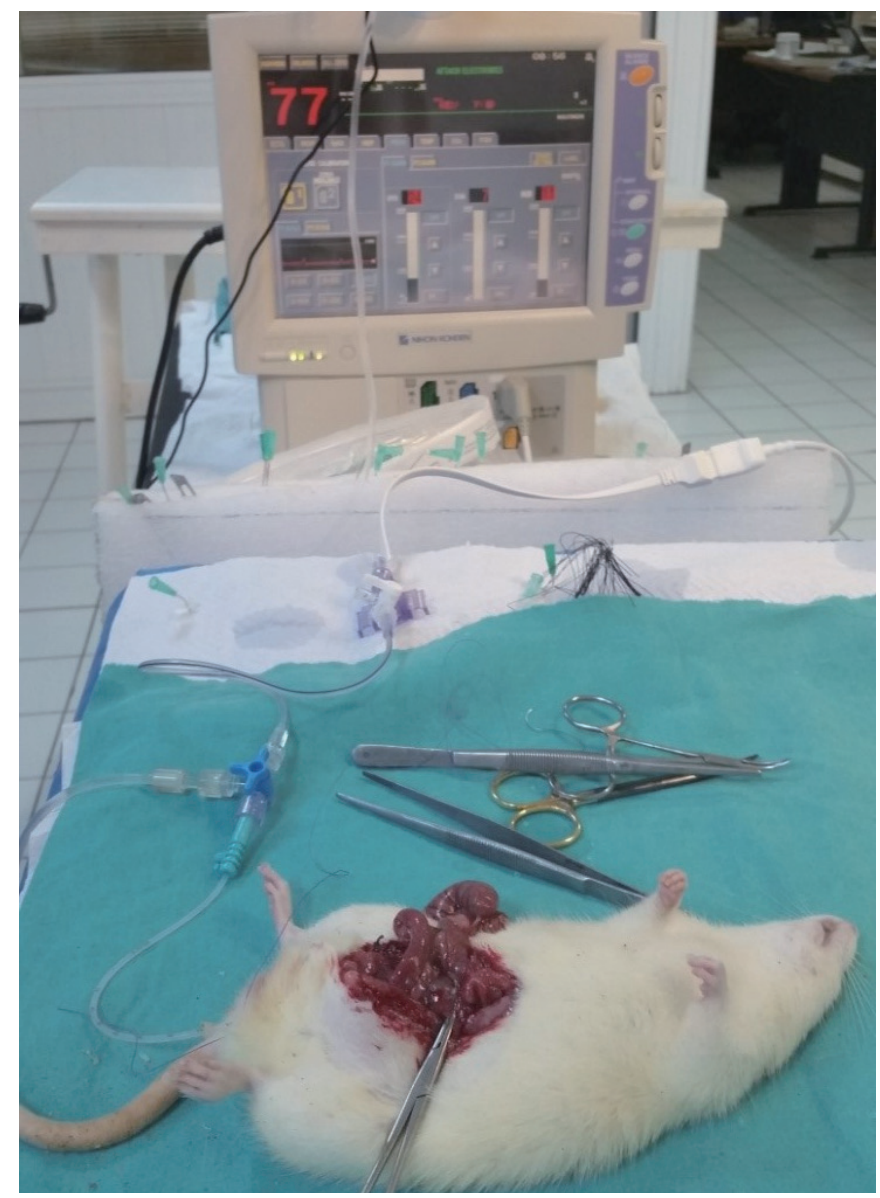

Fig. 2. Monitoring of bursting pressure. motic bursting pressure.

After the bursting pressure had been measured $1 \mathrm{~cm}$ proximal and $1 \mathrm{~cm}$ distal to the anastomosis, the colon segment was resected and divided into two equal parts passing through the anastomosis. One part was placed in $10 \%$ formaldehyde solution for histopathological examination, and the other was frozen at $-80^{\circ} \mathrm{C}$ for measurement of hydroxyproline levels. The rats were subsequently sacrificed by using the intracardiac blood collection method.

\section{Biochemical examination}

Samples were divided into 1-g specimens and hydrolyzed at $121^{\circ} \mathrm{C}$ for 5 hours in $1 \mathrm{~mL}$ of acidic buffer. Working material was obtained by centrifuging the resulting solution for 20 minutes at $5,000 \mathrm{rpm}$. Tissue hydroxyproline level was calculated as unit wet tissue weight ( $\mathrm{mg} / \mathrm{mg}$ tissue) by usina rat hydroxyproline enzymelinked immunosorbent assay kit (Hangzhou Eastbiopharm Co., Hangzhou, China).

The myeloperoxidase (MPO) level was measured in accordance with the method proposed by Grisham et al. [18]. After $300 \mathrm{mg}$ of intestinal mucosa had been homogenized with the addition of 5 $\mathrm{mL}$ of cold $0.02 \mathrm{M}$ ethylenediaminetetraacetic acid, the resulting solution was centrifuged at $20,000 \mathrm{~g}$ for 15 minutes at $+4^{\circ} \mathrm{C}$ to remove the supernatant. The resulting pellet was dissolved in a phosphate buffer of $0.05 \mathrm{M}$ potassium containing $0.5 \%$ of hexadecyl trimethyl ammonium bromide ( $\mathrm{pH}$ 5.4) before being centrifuged again. MPO determination was spectrophotometrically determined at a wavelength of $410 \mathrm{~nm}$ for the supernatant.

In accordance with the method proposed by Erel [19], total antioxidant status (TAS) was determined by using automatic measurement methods with 2,2'-Azino-bis (3-ethylbenzothiazoline6-sulfonic acid). Determination of total oxidant status (TOS) was based on measurement of the oxidation of ferrous ion-o-dianisidine complex to ferric iron in the oxidants present in the sample by using a spectrophotometric measurement [20]. The advanced oxidation protein product (AOPP) level was measured by using the spectrophotometric method described by Witko-Sarsat et al. [21].

\section{Pathological and histological examination}

Paraffin blocks prepared from tissue fragments were stored in $10 \%$ formaldehyde solution and stained with hematoxylin and eosin. Sections of $4.5 \mu$ in thickness were evaluated under a light microscope (BX51, Olympus, Tokyo, Japan) by a single pathologist blind to the sections' grouping. The scale hat that includes many factors associated with wound healing described by Biert et al. [22] and modified by Verhofstad et al. [23] was used.

\section{Statistical analysis}

Descriptive statistics (mean \pm standard deviation) were determined, and the results were used to produce charts in which the $95 \%$ confidence interval error bars indicate the means. The results 
of the analysis of the bursting pressure and the tissue hydroxyproline level by using the Shapiro-Wilks test showed a normal distribution. Nonparametric measurements and comparisons of the three groups in terms of pathology were performed by using the Kruskal-Wallis test. The Bonferroni-Dunn test was used as a post hoc test for significant conditions. Analysis of variance was performed for comparisons of the three groups in situations where a normal distribution was assumed, and Tukey test was performed for pairwise comparisons. IBM SPSS Statistics ver. 20.0 (IBM Co., Armonk, NY, USA), was used to determine the statistical significance of the results, with $\mathrm{P}<0.05$ indicating statistical significance.

\section{RESULTS}

\section{Anastomotic bursting pressure}

During the placement of instruments to measure the burst pressure, one subject in group I and two subjects in group II experienced separation of the anastomosis. These subjects were, therefore, excluded from the determination of the anastomosis bursting pressure. Analysis of the remaining subjects indicated that anesthesia and surgical treatment were not associated with mortality in any subject and that bursts had resulted from the anastomosis in all subjects.

Evaluation of the burst pressure measurements showed a normal distribution. Although the mean bursting pressure value was higher in group III than in groups I and II, no statistically significant differences was found among the group values $(P=0.222)$

Table 1. Anastomotic bursting pressure

\begin{tabular}{lcc}
\hline Group & Mean $\pm \mathrm{SD}(\mathrm{mmHg})$ & P-value \\
\hline I & $94.2 \pm 26.7$ & $0.222^{\mathrm{a}}$ \\
III & $86.0 \pm 22.8$ & \\
\hline
\end{tabular}

Group I, control group; group II, daily placebo enemas containing physiological saline; group III, daily $2 \%$ L-glutamine enemas.

$\mathrm{SD}$, standard deviation.

${ }^{a}$ One-way analysis of variance.
(Table 1). In accordance with these results, we concluded that administration of a Gln enema was not statistically significantly associated with the colonic anastomosis bursting pressure.

The results of comparisons of the biochemical measurements are shown in Table 2. The results of a post hoc analysis (binary comparison) of the comparative data obtained by biochemical measurements and identification of significant differences among the groups are shown in Table 3. As can be observed, the results of three tests of independent group differences indicated that the TAS, TOS, and MPO levels of at least one group were significantly different from those of the other groups. Analysis of the mean MPO levels revealed statistically significant differences between groups I and II and between groups II and III $(\mathrm{P}=0.048$ and $\mathrm{P}=$ 0.004 , respectively). Analysis of the mean TOS levels revealed group II had the highest mean TOS level and the presence of a statistically significant difference between groups II and III (P = 0.016). Analysis of the mean TAS levels revealed group III had the highest mean TAS level and the presence of a statistically significant difference between groups I and III $(P=0.048)$. Analysis of the mean AOPP levels revealed that group III had the lowest AOPP level and group II the highest level and the existence of no statistically significant differences among the groups.

Analysis of the mean tissue hydroxyproline levels revealed that group III had the highest mean level and the absence of any statistically significantly differences in levels among the three groups $(\mathrm{P}$

Table 3. Results of an analysis of the significant differences in biochemical measurements among the study groups

\begin{tabular}{lccc}
\hline \multirow{2}{*}{ Variable } & \multicolumn{3}{c}{ P-value } \\
\cline { 2 - 4 } & Group I vs. II & Group I vs. III & Group II vs. III \\
\hline TAS $(\mu \mathrm{mol} / \mathrm{L})^{\mathrm{a}}$ & 0.109 & $0.048^{*}$ & 0.999 \\
TOS $(\mu \mathrm{mol} / \mathrm{L})^{\mathrm{a}}$ & 0.560 & 0.422 & $0.016^{*}$ \\
Myeloperoxidase/ & $0.048^{*}$ & 0.534 & $0.004^{*}$ \\
$\quad$ wet tissue weight $(\mathrm{U} / \mathrm{g})^{\mathrm{b}}$ & & & \\
\hline
\end{tabular}

Group I, control group; group II, daily placebo enemas containing physiological saline; group III, daily $2 \%$ L-glutamine enemas.

TAS, total antioxidant status; TOS, total oxidant status.

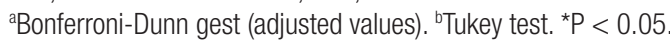

Table 2. Results of a comparison of biochemical measurements

\begin{tabular}{|c|c|c|c|c|}
\hline Variable & Group 1 & Group 2 & Group 3 & P-value \\
\hline TAS $(\mu \mathrm{mol} / \mathrm{L})^{\mathrm{a}}$ & $0.22 \pm 0.27$ & $0.93 \pm 0.74$ & $1.09 \pm 0.94$ & $0.039^{*}$ \\
\hline TOS $(\mu \mathrm{mol} / \mathrm{L})^{\mathrm{a}}$ & $46.78 \pm 17.74$ & $58.43 \pm 26.62$ & $35.24 \pm 13.53$ & $0.020^{*}$ \\
\hline $\mathrm{AOPP}(\mu \mathrm{mol} / \mathrm{L})^{\mathrm{a}}$ & $370.04 \pm 70.22$ & $303.70 \pm 131.23$ & $226.82 \pm 153.33$ & 0.083 \\
\hline Myeloperoxidase/wet tissue weight $(\mathrm{U} / \mathrm{g})^{b}$ & $162.23 \pm 67.73$ & $272.88 \pm 140.74$ & $114.31 \pm 71.30$ & $0.004^{*}$ \\
\hline Hydroxyproline/wet tissue weight $(\mu \mathrm{g} / \mathrm{g})^{\mathrm{a}}$ & $7.74 \pm 2.98$ & $5.88 \pm 6.33$ & $11.10 \pm 9.85$ & 0.369 \\
\hline
\end{tabular}

Values are presented as mean \pm standard deviation.

Group I, control group; group II, daily placebo enemas containing physiological saline; group III, daily 2\% L-glutamine enemas.

TAS, total antioxidant status; TOS, total oxidant status; AOPP, advanced oxidation protein product.

aKruskal-Wallis test. ${ }^{\mathrm{b}}$ one-way analysis of variance. ${ }^{*} \mathrm{P}<0.05$. 
Table 4. Results of comparison results of group score values

\begin{tabular}{lcccc}
\hline Criteria & Group I & Group II & Group III & P-value $^{\mathrm{a}}$ \\
\hline Necrosis & $1.2 \pm 0.63$ & $0.9 \pm 0.74$ & $0.7 \pm 0.74$ & 0.289 \\
PMN infiltration & $2.1 \pm 0.87$ & $2.0 \pm 0.66$ & $2.1 \pm 1.10$ & 0.904 \\
Lymphocyte infiltration & $1.6 \pm 0.84$ & $1.6 \pm 0.51$ & $1.2 \pm 0.63$ & 0.159 \\
Macrophage infiltration & $1.0 \pm 0.66$ & $1.0 \pm 0.47$ & $0.7 \pm 0.67$ & 0.423 \\
Edema extent & $1.2 \pm 0.78$ & $1.2 \pm 0.78$ & $1.0 \pm 0$ & 0.570 \\
$\begin{array}{l}\text { Mucosal epithelium } \\
\text { appearance }\end{array}$ & $2.4 \pm 0.51$ & $1.7 \pm 0.95$ & $1.6 \pm 0.96$ & 0.085 \\
$\begin{array}{c}\text { Submucosal-mucosal } \\
\text { layer appearanc }\end{array}$ & $1.7 \pm 0.95$ & $1.0 \pm 1.25$ & $0.8 \pm 1.03$ & 0.129 \\
\hline
\end{tabular}

Values are presented as mean \pm standard deviation.

Group I, control group; group II, daily placebo enemas containing physiological saline; group III, daily $2 \%$ L-glutamine enemas.

PMN, polymorphonuclear leukocyte.

${ }^{a}$ All comparisons performed using the Kruskal-Wallis test.

$=0.369$ ). Based on these data, we concluded that administration of a Gln enema has no statistically significant effect on the colonic anastomosis model in terms of tissue hydroxyproline levels.

\section{Histopathologic analysis}

Tissues taken from the perianastomotic section were histopathologically examined for scoring of mucosal ischemia, anastomotic wound healing, granulation tissue formation, and histological changes in local inflammatory response according to the criteria described by Biert et al. [22] and modified by Verhofstad et al. [23]. The results of comparison of the scores of the groups are shown in Table 4. Analysis of the necrosis scores revealed the absence of any statistically significant differences among the three groups ( $\mathrm{P}=0.289)$. Likewise, analysis of the groups in terms of polymorphonuclear leukocyte, lymphocyte, and macrophage intensity revealed the absence of any statistically significant differences $(\mathrm{P}=0.904, \mathrm{P}=0.159$, and $\mathrm{P}=0.423$, respectively). Analysis of mean edema, mucosal epithelial damage, and submucosal-mucosal bridging scores revealed that group III had the mean lowest scores for all three parameters but that the mean scores of groups III and I and of groups III and II did not differ significantly ( $\mathrm{P}=$ $0.570, \mathrm{P}=0.085$, and $\mathrm{P}=0.129$, respectively).

\section{DISCUSSION}

Surgical resection and primary anastomosis are standard treatments for colorectal cancer and benign diseases such as diverticulitis and ulcerative colitis. Despite recent developments in colorectal surgery techniques, the mean anastomosis leak rate remains at $11 \%[3,4]$. Anastomotic leaks cause morbidity, mortality, and an increase in the permanent stoma rate while contributing to recurrent malignant disease [24]. In consideration of these negative outcomes, development of technical applications and pharmacological agents that can increase anastomotic healing and reduce the leakage rate has been a primary focus of basic surgical research. Although different pharmaceutical agents, including ileoprost, tacrolimus, eritroprotein, growth hormone, hyperbaric oxygen, and inhibitors of matrix metallaproteinaz, have been examined in experimental studies, none has been found superior in promoting anastomotic healing [25].

Gln, the most commonly found amino acid in the body, plays an important role in many metabolic reactions [5]. As such, Gln has become the one of the most-researched nutrients in the field of nutrition and a primary focus of metabolic support studies [26]. Surgery, trauma, sepsis, and other serious conditions decrease the concentration of the intracellular Gln pool, thus rapidly depleting body stores [7, 8]. Although Gln depletion is inevitable in such conditions, replacement can improve nitrogen balance and immunosupression [27]. Gln is a preferred respiratory fuel for rapidly dividing cells such as fibroblasts, lymphocytes, and epithelial cells, as well as intestinal mucosa cells [28]. High-speed intake of Gln by these rapidly dividing cells provides ideal conditions for the synthesis of important molecules such as glutathione and nucleotides [29]. In addition, prolin, one of the products of Gln metabolism, is required for the production of collagen $[5,30]$.

Recent studies of Gln in the intestinal tracts of experimental animal models have observed that a $2 \%$ to $3 \%$ Gln solution may prevent atrophy in the large and the small bowels [30, 31]. Based on such findings, Gln has been hypothesized to prevent bacterial translocation that can lead to septicemia and multiple organ failure by helping protect the integrity of the intestinal tract $[32,33]$. Gln not only also initiates the synthesis of glutathione, a major antioxidant that protects against free radical damage, but may also play a role in preventing tissue damage after shock and postischemic reperfusion [34]. In addition to serving as an effective barrier helping protect the intestine through improving its defense capacity, Gln facilitates the most appropriate immune defenses via several mechanisms. When the plasma Gln level is low, the Tlymphocyte level is suppressed [35], the neutrophil bactericidal function is impaired [36], and the macrophage phagocytic activity and the interleukin-1 production are decreased [37].

Many studies have examined the effect of Gln provision alone on anastomotic healing. In an evaluation of the effects of oral Gln on colon anastomosis, Da Costa et al. [5] found the bursting pressure in the study group to be significantly higher than that in the control group. Gokpınar et al. [14] showed that addition of Gln to the nutritional protocol significantly decreased the negative outcomes of late enteral feeding on anastomotic resistance. Other experimental studies have examined the effects of Gln provision, together with that of other agents, on anastomosis. Among them, Girgin et al. [38] found that provision of pulsed electromagnetic field therapy, together with Gln, had prositive effects on anastomosis healing. In a study use of Gln with symbiotics, Sapidis et al. [39] found that it prevented septic complications by reducing bacterial translocation and had positive effects on anastomosis healing. In a study of the intra-abdominal sepsis model, Donmez et al. 
[40] found that the administration of growth hormone with Gln had a synergistic effect on anastomotic healing. In an examination of the effects of topical use of Gln in a colitis model, Israeli et al. [15] and Fillmann et al. [16] found that prophylactic use reduced colonic inflammation. In an experimental colitis model, Kaya et al. [41] found that administration of an L-Gln enema accelerated mucosal healing and regeneration. Wischmeyer et al. [17] showed that topically used Gln was useful in $60 \%$ of cases of chronic pouchitis.

Use of an enema, the process of administering liquid into the rectum and colon through the anus for medical reasons, was first mentioned in the Ebers Papyrus in 1500 BC [42]. Common current uses of enemas include constipation relief, preoperative bowel preparation, administration of postoperative analgesia in children, and treatments for inflammatory bowel disease, radiation proctitis, pouchitis, and solitary rectal ulcers [43]. Although the literature identifies few possible adverse effects of an enema, it is known to have potentially life-threatening side effects, depending on the patient's position during enema application. These effects include perforation by the tip of the enema device, localized weakness of the rectal wall, and obstruction [44]. In practice, surgeons attempt to avoid using an enema to prevent trauma in the anastomosis area.

To the authors' knowledge, no study before ours has examined the effects of enema administration after an anastomosis on healing. However, several studies have studied the other effects of enema administration. In a study of anastomotic integrity after a rectal anastomosis in which a contrast enema was administered an average of 6-8 days after the anastomosis, Shorthous et al. [45] reported that only one of 112 patients experienced perforation, depending on the application. The healing of an intestinal anastomosis can be considered a mechanical, biochemical, or histopathological process [46]. Among all parameters, the bursting pressure is considered a relatively accurate indication of anastomotic healing pathophysiology in the early period [47]. Analysis of the bursting pressures in this study revealed that although the subjects administered a Gln enema (group III) had the highest bursting presssure, no statistically significant differences in this parameter were observed among the three groups $(P=0.222)$. In accordance, studies examining the effects of both Gln alone and the addition of Gln to specialized forms of nutrition on anastomotic healing, have shown that it has positive effects on the bursting pressure [12, 14]. Based on their findings, De Costa et al. [5] concluded that Gln had a positive effect on an anastomosis by increasing the breaking force.

Biochemical determination of anastomotic healing is indicated by the hydroxyproline content of collagen and, thus, is limited by the collagen content [46]. Another limiting factor is that usage of hydroxyproline level alone as a parameter to determine the level of healing can sometimes provide inaccurate results $[46,48]$. The main elements determining the strength of the intestinal anastomosis is the mass of collagen and the quality of collagen fibril [49].
While anastomosis collagen content and mechanical parameters are often found not to be correlated, this finding may be due to a greater focus on collagen mass than on collagen quality $[46,48]$. Evaluation of tissue hydroxyproline levels in the current study revealed that although group III had the highest mean hydroxyproline levels, no statistically significant differences were observed among the three groups $(\mathrm{P}=0.369)$.

In a comparison of early or late enteral nutrition with and without addition of Gln, Gokpinar et al. [14] found that Gln addition to either early or late enternal nutriton did not affect collagen synthesis to a statistically significant extent. Supporting this finding, similar studies found that the addition of Gln to enteral nutrition did not significantly increase tissue hydroxyproline levels [50, 51]. On the other hand, based on their finding that the type-1 (mature) collagen ratio in the anastomosis area was significantly higher, Gokpinar et al. [14] argued that Gln addition supported anastomosis healing by increasing the quality of collagen.

The current study evaluated the effects of administration of Gln enema on anastomotic healing as histopathologically defined by Biert et al. [22] according to a modified scoring system developed by Verhofstad et al. [23]. When necrosis scores were examined, no statistically signficant differences were observed among the three study groups $(\mathrm{P}=0.289)$. However, this lack of statistical signficance can be explained by the inclusion of an insufficient number of subjects. Neverthess, a notable finding was the lack of necrosis observed in half of group III.

Administration of Gln has been found to have similar positive effects after radiation damage [52], after ischemia/reperfusion damage [53], and after oxidative stress [54], as well as on intestinal healing in rats suffering from malnutrition [10]. In a colitis model, Israeli et al. [15] found that application of topical Gln reduced inflammatory damage, leading them to hypothesize that Gln application before colitis maintains the resistance of the colonic mucosa against oxidative stress.

MPO is an enzyme used in the creation of toxic agents that destroy the agents phagocyted by neutrophils. In experimental studies, MPO activity is widely used as an index of neutrophil infiltration to determine the severity of inflammation [55]. The effect of the severity of inflammation on the anastomosis is an important factor affecting the healing process as excessive or prolonged inflammation can cause insufficient collagen synthesis and lead to anastomotic leakage or stricture $[56,57]$. Comparison of MPO levels in the current study revealed that they were highest in group II and lowest in group III and that statistically significant differences existed between groups I and II and between groups II and III ( $\mathrm{P}=0.048$ and $\mathrm{P}=0.004$, respectively). These results suggest that the effect of local trauma due to a physiological saline enema increases the severity of the inflammation, which can be neutralized by Gln.

In an organism, the antioxidant defense system against the injurious effects of reactive oxygen species is enhanced. Under normal conditions, the injurious effects of toxic products are limited, 
thereby minimizing tissue damage due to oxidative damage. Antioxidants can yield direct effects on the inactivation of oxidants [58]. Studies that have examined extrinsically added glutathione or Gln as a glutathione precursor have found that it has a protective effect against oxidative stress [59]. Many different methods are used to measure the markers of oxidative stress and to evaluate the extent of oxidative stress and antioxidant status. As measurement of these markers separately is time-consuming and costly [60], measurements of the TOS and the TAS have become increasingly common $[19,20]$. When the present study examined TOS levels, group II was found to have the highest mean level, and a statistically significant difference was found between groups II and III $(\mathrm{P}=0.016)$. When TAS levels were examined, group III was found to have the highest mean level, and a statistically significant difference was found between groups I and III ( $\mathrm{P}=$ 0.048). These results suggest that the oxidative stress experienced by group II was neutralized by application of Gln and that Gln functioned as a powerful antioxidant for group III. When AOPP values were examined, group III was found to have the highest mean level, but no significant differences were found among the three groups. To the authors' knowledge, no other studies have examined the TAS and the TOS levels in perianastomotic tissue, preventing comparison of these findings with previous findings.

Despite recent developments in colorectal surgery, anastomosis complications continue to cause difficult-to-manage conditions. Therefore, prevention of complications has become a prime focus of surgical research. As the current study was the first to investigate the effects of the administration of a Gln enema on anastomotic healing in an experimental model of colon anastomosis, the findings presented here are important. Assessments of the anastomotic bursting pressure, hydroxyproline levels, and histological scores as indicators of anastomotic healing indicated that the administration of a Gln enema had positive effects. Although the differences in these values among the control, placebo, and experimental groups (groups I, II, and II, respectively) were not statistically significant, such lack of significance may have been due to the examination of a limited number of subjects.

Despite the potentially positive effects of a Gln enema, trauma due to enema application may result in a local inflammatory reaction, which may adversely affect wound healing. Analysis of the $\mathrm{MPO} /$ wet tissue weight, an accepted indicator of excessive neutrophil infiltration, revealed a statistically significantly higher level in group II compared to group I $(\mathrm{P}=0.048)$ and low levels in group III (group III to II pairwise comparison, $\mathrm{P}=0.004$ ). Analyses of the TAS and the TOS demonstrated that a Gln enema had a positive local antioxidant effect on the colonic mucosa.

The results of this study indicate that administration of a Gln enema may have a positive effect on anastomosis healing. On the basis of these findings, preoperative application of a Gln enema should be evaluated as a means of decreasing the traumatic effects of an enema and identifying its applicability in surgical practice. Future research should compare the effects of Gln-supplemented nutrition with those of a Gln enema to determine the most appropriate means of Gln provision.

\section{CONFLICT OF INTEREST}

No potential conflict of interest relevant to this article was reported.

\section{REFERENCES}

1. Attard JA, Raval MJ, Martin GR, Kolb J, Afrouzian M, Buie WD, et al. The effects of systemic hypoxia on colon anastomotic healing: an animal model. Dis Colon Rectum 2005;48:1460-70.

2. Parra-Membrives P, Ruiz-Luque V, Escudero-Severin C, AguilarLuque J, Mendez-Garcia V. Effect of pentoxifylline on the healing of ischemic colorectal anastomoses. Dis Colon Rectum 2007;50: 369-75.

3. Shogan BD, Carlisle EM, Alverdy JC, Umanskiy K. Do we really know why colorectal anastomoses leak? J Gastrointest Surg 2013; 17:1698-707.

4. Peeters KC, Tollenaar RA, Marijnen CA, Klein Kranenbarg E, Steup WH, Wiggers T, et al. Risk factors for anastomotic failure after total mesorectal excision of rectal cancer. Br J Surg 2005;92: 211-6.

5. da Costa MA, Campos AC, Coelho JC, de Barros AM, Matsumoto HM. Oral glutamine and the healing of colonic anastomoses in rats. JPEN J Parenter Enteral Nutr 2003;27:182-5.

6. Lacey JM, Wilmore DW. Is glutamine a conditionally essential amino acid? Nutr Rev 1990;48:297-309.

7. Balzola FA, Boggio-Bertinet $\mathrm{D}$. The metabolic role of glutamine. Minerva Gastroenterol Dietol 1996;42:17-26.

8. Vinnars E, Bergstom J, Furst P. Influence of the postoperative state on the intracellular free amino acids in human muscle tissue. Ann Surg 1975;182:665-71.

9. Windmueller HG, Spaeth AE. Identification of ketone bodies and glutamine as the major respiratory fuels in vivo for postabsorptive rat small intestine. J Biol Chem 1978;253:69-76.

10. Tannuri U, Carrazza FR, Iriya K. The effects of glutamine-supplemented diet on the intestinal mucosa of the malnourished growing rat. Rev Hosp Clin Fac Med Sao Paulo 2000;55:87-92.

11. Campos FG, Waitzberg DL, Logulo AF, Mucerino DR, HabrGama A. The role of glutamine in nutrition in clinical practice. Arq Gastroenterol 1996;33:86-92.

12. Demetriades H, Botsios D, Kazantzidou D, Sakkas L, Tsalis K, Manos K, et al. Effect of early postoperative enteral feeding on the healing of colonic anastomoses in rats. Comparison of three different enteral diets. Eur Surg Res 1999;31:57-63.

13. Potsic B, Holliday N, Lewis P, Samuelson D, DeMarco V, Neu J. Glutamine supplementation and deprivation: effect on artificially reared rat small intestinal morphology. Pediatr Res 2002;52:430-6.

14. Gokpinar I, Gurleyik E, Pehlivan M, Ozcan O, Ozaydin I, Aslaner A, et al. Early enteral and glutamine enriched enteral feeding 
ameliorates healing of colonic anastomosis: experimental study. Ulus Travma Acil Cerrahi Derg 2006;12:17-21.

15. Israeli E, Berenshtein E, Wengrower D, Aptekar L, Kohen R, Zajicek G, et al. Prophylactic administration of topical glutamine enhances the capability of the rat colon to resist inflammatory damage. Dig Dis Sci 2004;49:1705-12.

16. Fillmann H, Kretzmann NA, San-Miguel B, Llesuy S, Marroni N, Gonzalez-Gallego J, et al. Glutamine inhibits over-expression of pro-inflammatory genes and down-regulates the nuclear factor kappaB pathway in an experimental model of colitis in the rat. Toxicology 2007;236:217-26.

17. Wischmeyer P, Pemberton JH, Phillips SF. Chronic pouchitis after ileal pouch-anal anastomosis: responses to butyrate and glutamine suppositories in a pilot study. Mayo Clin Proc 1993;68:978-81.

18. Grisham MB, Everse J, Janssen HF. Endotoxemia and neutrophil activation in vivo. Am J Physiol 1988;254(5 Pt 2):H1017-22.

19. Erel O. A novel automated direct measurement method for total antioxidant capacity using a new generation, more stable ABTS radical cation. Clin Biochem 2004;37:277-85.

20. Erel O. A new automated colorimetric method for measuring total oxidant status. Clin Biochem 2005;38:1103-11.

21. Witko-Sarsat V, Friedlander M, Capeillere-Blandin C, NguyenKhoa T, Nguyen AT, Zingraff J, et al. Advanced oxidation protein products as a novel marker of oxidative stress in uremia. Kidney Int 1996;49:1304-13.

22. Biert J, Seifert WF, Verhofstad AA, Wobbes T, de Man BM, Hoogenhout J, et al. A semiquantitative histological analysis of repair of anastomoses in the rat colon after combined preoperative irradiation and local hyperthermia. Radiat Res 1998;149:372-7.

23. Verhofstad MH, Lange WP, van der Laak JA, Verhofstad AA, Hendriks T. Microscopic analysis of anastomotic healing in the intestine of normal and diabetic rats. Dis Colon Rectum 2001;44:423-31.

24. Krarup PM, Nordholm-Carstensen A, Jorgensen LN, Harling H. Anastomotic leak increases distant recurrence and long-term mortality after curative resection for colonic cancer: a nationwide cohort study. Ann Surg 2014;259:930-8.

25. Oines MN, Krarup PM, Jorgensen LN, Agren MS. Pharmacological interventions for improved colonic anastomotic healing: a meta-analysis. World J Gastroenterol 2014;20:12637-48.

26. Ziegler TR, Bazargan N, Leader LM, Martindale RG. Glutamine and the gastrointestinal tract. Curr Opin Clin Nutr Metab Care 2000;3:355-62.

27. Miller AL. Therapeutic considerations of L-glutamine: a review of the literature. Altern Med Rev 1999;4:239-48.

28. Wallace C, Keast D. Glutamine and macrophage function. Metabolism 1992;41:1016-20.

29. Higashiguchi T, Hasselgren PO, Wagner K, Fischer JE. Effect of glutamine on protein synthesis in isolated intestinal epithelial cells. JPEN J Parenter Enteral Nutr 1993;17:307-14.

30. Jacobs D, Evans DA, O’Dwyer ST, Smith RJ, Wilmore DW. Trohic effects of glutamine-enriched parenteral nutrition. JPEN J Parenter Enteral Nutr 1988;12(suppl):6.
31. Grant JP, Snyder PJ. Use of L-glutamine in total parenteral nutrition. J Surg Res 1988;44:506-13.

32. Hobsley M, Imms FJ. Physiology in surgical patients. London: Edward Arnold; 1992.

33. Souba WW, Herskowitz K, Austgen TR, Chen MK, Salloum RM. Glutamine nutrition: theoretical considerations and therapeutic impact. JPEN J Parenter Enteral Nutr 1990;14(5 Suppl):237S-243S.

34. van der Hulst RR, van Kreel BK, von Meyenfeldt MF, Brummer RJ, Arends JW, Deutz NE, et al. Glutamine and the preservation of gut integrity. Lancet 1993;341:1363-5.

35. Hong RW, Rounds JD, Helton WS, Robinson MK, Wilmore DW. Glutamine preserves liver glutathione after lethal hepatic injury. Ann Surg 1992;215:114-9.

36. O’Riordain MG, Fearon KC, Ross JA, Rogers P, Falconer JS, Bartolo DC, et al. Glutamine-supplemented total parenteral nutrition enhances T-lymphocyte response in surgical patients undergoing colorectal resection. Ann Surg 1994;220:212-21.

37. Ogle CK, Ogle JD, Mao JX, Simon J, Noel JG, Li BG, et al. Effect of glutamine on phagocytosis and bacterial killing by normal and pediatric burn patient neutrophils. JPEN J Parenter Enteral Nutr 1994;18:128-33.

38. Girgin S, Gedik E, Ozturk H, Akpolat V, Kale E, Buyukbayram H, et al. Effects of combined pulse electromagnetic field stimulation plus glutamine on the healing of colonic anastomosis in rats. Dig Dis Sci 2009;54:745-50.

39. Sapidis N, Tziouvaras C, Ioannidis O, Kalaitsidou I, Botsios D. The effect of glutamine and synbiotics on the healing of colonic anastomosis. Rev Esp Enferm Dig 2014;106:255-62.

40. Donmez R, Oren D, Ozturk G, Kisaoglu A, Ozogul B, Atamanalp SS. The combined effects of glutamine and growth hormone on intestinal anastomosis in the rat intra-abdominal sepsis model. J Surg Res 2013;182:142-5.

41. Kaya E, Ceylan A, Kara N, Guven H, Yildiz L. The effect of L-glutamine on mucosal healing in experimental colitis is superior to short-chain fatty acids. Turk J Gastroenterol 2007;18:89-94.

42. Viso L, Uriach J. The "guardians of the anus" and their practice. Int J Colorectal Dis 1995;10:229-31.

43. Ramakrishnan K, Scheid DC. Enemas: a "purge" story. Internet J Gastroenterol 2004;3:1.

44. Niv G, Grinberg T, Dickman R, Wasserberg N, Niv Y. Perforation and mortality after cleansing enema for acute constipation are not rare but are preventable. Int J Gen Med 2013;6:323-8.

45. Shorthouse AJ, Bartram CI, Eyers AA, Thomson JP. The water soluble contrast enema after rectal anastomosis. Br J Surg 1982; 69:714-7.

46. Verhofstad MH, Hendriks T. Diabetes impairs the development of early strength, but not the accumulation of collagen, during intestinal anastomotic healing in the rat. Br J Surg 1994;81:1040-5.

47. Brasken P. Healing of experimental colon anastomosis. Eur J Surg Suppl 1991;(566):1-51.

48. Bucknall TE. The effect of local infection upon wound healing: an experimental study. Br J Surg 1980;67:851-5. 
49. Goligher JC, Graham NG, De Dombal FT. Anastomotic dehiscence after anterior resection of rectum and sigmoid. Br J Surg 1970;57:109-18.

50. McCauley R, Platell C, McCulloch R, Hall J. The influence of branched chain amino acids on colonic atrophy and anastomotic strength in the rat. Aust N Z J Surg 1991;61:49-53.

51. Cihan A, Oguz M, Acun Z, Ucan BH, Armutcu F, Gurel A, et al. Comparison of early postoperative enteral nutrients versus chow on colonic anastomotic healing in normal animals. Eur Surg Res 2004;36:112-5.

52. Klimberg VS, Souba WW, Dolson DJ, Salloum RM, Hautamaki $\mathrm{RD}$, Plumley DA, et al. Prophylactic glutamine protects the intestinal mucosa from radiation injury. Cancer 1990;66:62-8.

53. Harward TR, Coe D, Souba WW, Klingman N, Seeger JM. Glutamine preserves gut glutathione levels during intestinal ischemia/ reperfusion. J Surg Res 1994;56:351-5.

54. Musch MW, Hayden D, Sugi K, Straus D, Chang EB. Cell-specific induction of hsp72-mediated protection by glutamine against oxidant injury in IEC18 cells. Proc Assoc Am Physicians 1998;110:
136-9.

55. Wang P, Li Y, Li J. Influence of hydroxyethyl starch on healing of colonic anastomosis in a rat model of peritonitis. J Invest Surg 2009; 22:375-82.

56. Stumpf M, Klinge U, Mertens PR. Anastomotic leakage in the gastrointestinal tract-repair and prognosis. Chirurg 2004;75:1056-62.

57. Buckmire MA, Parquet G, Greenway S, Rolandelli RH. Temporal expression of TGF-beta1, EGF, and PDGF-BB in a model of colonic wound healing. J Surg Res 1998;80:52-7.

58. Mathers J, Fraser JA, McMahon M, Saunders RD, Hayes JD, McLellan LI. Antioxidant and cytoprotective responses to redox stress. Biochem Soc Symp 2004;(71):157-76.

59. Amores-Sanchez MI, Medina MA. Glutamine, as a precursor of glutathione, and oxidative stress. Mol Genet Metab 1999;67:100-5.

60. Tarpey MM, Wink DA, Grisham MB. Methods for detection of reactive metabolites of oxygen and nitrogen: in vitro and in vivo considerations. Am J Physiol Regul Integr Comp Physiol 2004;286: R431-44. 